\title{
LOS DIEZMOS DE JEREZ DE LA FRONTERA EN EL SIGLO XVIII. CONSIDERACIONES SOBRE LA FUENTE DOCUMENTAL
}

\author{
JESÚS MANUEL GONZÁLEZ BELTRÁN | UNIVERSIDAD DE CÁDIZ
}

ORCID iD: 0000-0002-7273-5159

\begin{abstract}
RESUMEN
En este artículo se plantean dos objetivos. Primero, analizar la veracidad de los datos de las fuentes diezmales incidiendo en cuestiones tales como los exentos, los excusados y el fraude. Y segundo, comprobar la insuficiencia de dicha fuente como medio para obtener la producción bruta agraria, en este caso del trigo y la cebada. La fuente utilizada son las subastas, durante el siglo XVIII, de los distintos conceptos del diezmo que se arrendaban en la vicaría de Jerez de la Frontera, perteneciente al arzobispado de Sevilla, en especial, la renta de pan terciado.
\end{abstract}

PALABRAS CLAVE

Diezmo, producción agrícola, cosechas, Andalucía, siglo XVIII

\section{THE TITHES OF JEREZ DE LA FRONTERA IN THE XVIII CENTURY. CONSIDERATIONS ON THE DOCUMENTARY SOURC}

\begin{abstract}
This article raises two aims. First, to analyze the veracity of the data from the tithing records, bearing in mind matters such as the exentos, the excusados and the fraud. And second, to show how inadequate was the above mentioned source, to obtain the agricultural gross production, in our case, of wheat and barley. The source used was the auctions of the different goods paid as tithe, especially the income from the pan terciado, that were leased in the vicariate of Jerez de la Frontera, belonging to the Archdiocesan of Seville.
\end{abstract}

\section{KEYWORDS}

Tithe, agricultural production, harvests, Andalusia, 18th century 


\section{INTRODUCCIÓN}

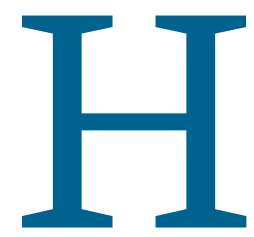

an transcurrido ya más de 50 años desde que historiadores franceses empezaran a utilizar, con el objetivo de conocer e interpretar determinadas conductas y procesos demográficos y, especialmente, económicos de la sociedad francesa de los periodos medieval y moderno, las fuentes fiscales eclesiásticas, en concreto la documentación relativa a los diezmos ${ }^{1}$. Las posibilidades que ofrecía el uso de las series decimales, junto con las primeras advertencias sobre sus limitaciones, quedaron recogidas en dos significativos encuentros que tuvieron lugar en la década de los 70 del siglo pasado ${ }^{2}$.

Por esas fechas, y debido en gran medida a la influencia de la historiografía francesa sobre los investigadores españoles, comienzan éstos a hacer un uso sistemático de la documentación decimal, tanto para puntuales aproximaciones, planteadas en ocasiones en forma

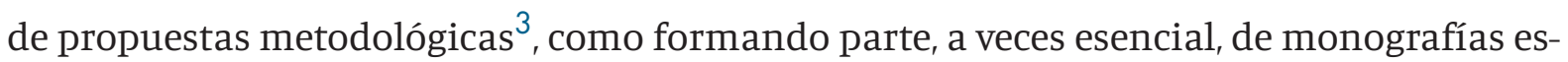
tructurales sobre determinadas comarcas o ciudades ${ }^{4}$. Igualmente, aplicando dichas fuentes a estudios generales relativos al desarrollo de la producción o a la evolución demográfica desde perspectivas maltusianas ${ }^{5}$.

No hubo prácticamente ninguna región española en la que se dejara de trabajar sobre la documentación decimal, en ello incidió la cercanía y disponibilidad archivística de esta 1 Buena prueba de ello son los excelentes trabajos, ya clásicos, de GOUBERT, Pierre. Beauvais et le Beauvaisis de 1600
à 1730, París, SEVPEN, 1960 y LE ROY LADURIE, Emmanuel. Les paysans de Languedoc, París-La Haya, SEVPEN, 1966.
2 Las actas editadas por GOY, Joseph y LE ROY LADURIE, Emmanuel. Les fluctuations du produit de la dîme.
Conjuncture decimale et domaniale de la fin du Moyen Age au XVIII siècle, París-La Haya, Ecole Pratique des Hautes
Etudes et Mouton, 1972 y Prestations paysannes, dimes, rente fonciére et mouvement de la production agricole à
l'epoque prèindustrielle, París-La Haya-New York, Mouton, 1982.
3 EIRAS, Antonio. Evolución del producto decimal en Galicia a finales del Antiguo Régimen: primeras series
diezmales, Actas de las I Jornadas de Metodología Aplicada a las Ciencias Históricas. Metodología de la Historia
Moderna. Economía y demografía, Santiago de Compostela, Universidad de Santiago de Compostela, 1975, Pp. 51-
90; GARCÍA SANZ, Ángel. Los diezmos del obispado de Segovia del siglo XV al XIX: problemas de método, modos de
percepción y regímenes sucesivos de explotación, Actas de las I Jornadas de Metodología..., Pp. 143-152; y RODRÍGUEZ
MOLINA, José. El diezmo eclesiástico en el valle del Guadalquivir, su utilidad para el estudio de la historia económica,
Actas I Congreso de Historia de Andalucía, tomo I, Córdoba, Monte de Piedad y Caja de Ahorros de Córdoba, 1978, PP.
429-434.

4 A modo de ejemplo, GARCÍA SANZ, Ángel. Desarrollo y crisis del Antiguo Régimen en Castilla la Vieja, Madrid, Akal, 1986, PP. 378-394; BARRIO GOZALO, Maximiliano. Estudio socio-económico de la Iglesia de Segovia en el siglo XVIII, Segovia, Caja de Ahorros de Segovia, 1982; y MELÓN JIMÉNEZ, Miguel Ángel. Extremadura en el Antiguo Régimen. Economía y sociedad en tierras de Cáceres 1700-1814, Mérida, Editora Regional de Extremadura, 1989.

5 Destacar ANES, Gonzalo. Las crisis agrarias en la España Moderna, Madrid, Taurus Ediciones S.A., 1970; LADERO QUESADA, Miguel Ángel y GONZÁLEZ JIMÉNEZ, Manuel. Diezmo eclesiástico y producción de cereales en el reino de Sevilla (1408-1503), Sevilla, Universidad de Sevilla, 1979; y la obra resumen de las investigaciones de PONSOT, Pierre. Atlas de historia económica de la Baja Andalucía (siglos XVI-XIX), Sevilla, Editoriales Andaluzas Unidas, 1986. 
fuente, conservada, preferentemente, en los archivos diocesanos, pero que, parcialmente, podía ser localizada en otros archivos eclesiásticos tales como los parroquiales, conventuales y hospitalarios de muchas localidades. Para el caso concreto del territorio andaluz, además de los trabajos ya citados, habría que hacer alusión, para la Edad Moderna, a los estudios de Muñoz Dueñas sobre el obispado de Córdoba; de Traverso Ruiz que trata la diócesis de Cádiz; de Martín Riego con su aportación sobre el arzobispado sevillano; y de Lara Ramos referido a la diócesis de Guadix 6 .

Pero las investigaciones sobre los diezmos o basadas en los mismos pasaron, en un corto espacio temporal, de un desarrollo súbito y fructífero a un olvido progresivo, que, salvo esporádicos títulos, ha hecho desaparecer la temática decimal de la historiografía actual ${ }^{7}$. En esta situación han incidido, sobre todo, los cambios en las tendencias e intereses a la hora de analizar el objeto histórico. Es un hecho constatado que materias como la historia económica o, más en concreto, la historia rural, las más relacionadas con la utilización de las fuentes decimales, han perdido protagonismo frente a otras líneas de investigación. Y este abandono, no deja de ser una falta censurable, ya que, a pesar de lo mucho que se realizó, queda bastante por explotar de la rica y abundante documentación decimal, máxime cuando las nuevas tecnologías informáticas amplían las posibilidades de tratamiento de la información seriada. No estaría de más un relanzamiento renovado de las investigaciones relativas al diezmo.

\section{CONSIDERACIONES SOBRE LAS FUENTES DECIMALES. LOS HACIMIENTOS DEL DIEZMO DE JEREZ DE LA FRONTERA}

El estudio presentado se sustenta sobre una serie de arrendamientos de diezmos localizada, algo extraño, en un archivo no eclesiástico, en concreto en el archivo municipal de Jerez

6 MUÑOZ DUEÑAS, María Dolores. El diezmo en el obispado de Córdoba (1750-1845), Córdoba, Cajasur, 1988 ; TRAVERSO RUIZ, Francisco. Los diezmos del obispado de Cádiz: percepción, distribución y evolución (1645-1835), Tesis doctoral inédita, Cádiz, 1994; MARTÍN RIEGO, Manuel. Diezmos eclesiásticos, rentas y gastos de la mesa arzobispal hispalense (1750-1800), Sevilla, Caja Rural de Sevilla, 1990; LARA RAMOS, Antonio. Iglesia y poder: propiedad y diezmos en la crisis del Antiguo Régimen. Guadix y su obispado (1750-1808), Granada, Universidad de Granada, 2001. También incluir, para completar las jurisdicciones eclesiásticas andaluzas, los trabajos de GARZÓN PAREJA, Manuel. Diezmos y tributos del clero de Granada, Granada, Archivo de la Real Chancillería, 1974 y BENÍTEZ SÁNCHEZ-BLANCO, Rafael. “Las rentas eclesiásticas del obispado de Málaga a mediados del siglo XVII", Actas I Congreso de Historia de Andalucía..., Tomo I, pp. 119-129.

7 Una de las pocas aportaciones recientes es la de LÓPEZ-SALAZAR PÉREZ, Jerónimo. La evolución diferencial de la producción agrícola. Obreros y terzuelos en el arzobispado de Toledo (1501-1700), Cuadernos de Historia Moderna, 43-1 (2018), pp. 9-64. 
de la Frontera (Cádiz) $^{8}$. Dicha ciudad presenta una peculiaridad, su término se encuentra dividido entre dos jurisdicciones eclesiásticas: el arzobispado de Sevilla y el obispado de Cádiz, en función de si las tierras se hallaban al norte o al sur, respectivamente, del río Guadalete. Los hacimientos o arrendamientos de rentas utilizados para este trabajo corresponden a la parte de la jurisdicción sevillana, por otro lado la más importante, ya que, además de incluir en ella el núcleo urbano, representa el 66,95\% del conjunto de la superficie del término, incrementándose dicho porcentaje hasta el 90,86\% si se toma como elemento de cómputo las tierras dedicadas al cultivo de cereales. No obstante, a efectos de ofrecer una visión completa de la localidad, se ha incluido, en algunos aspectos, el montante de los diezmos correspondientes al obispado gaditano?

Todas las rentas decimales de Jerez de la Frontera correspondientes al arzobispado sevillano eran arrendadas mediante pública subasta ${ }^{10}$. Para proceder a los arrendamientos las rentas eran agrupadas en tres bloques. El primero correspondía a las rentas menudas y en ellas se integran las siguientes: huertas; semillas menores; corderos y lana; potros, becerros y jumentos; y cabras y cerdos. El segundo bloque lo componían dos rentas: una la del vino y otra la de zahína y maíz. Finalmente, el tercer conjunto correspondía a las llamadas rentas de pan, compuestas por: pan terciado; semillas mayores; excusados; miel y cera; renta mayor de monjas y frailes; renta menor de monjas y frailes; maravedíes de determinados conventos; y menudos de Crespellina.

Son precisamente algunas de estas rentas de pan las que se analizan en este trabajo. Así, se ha recopilado la información relativa a las subastas de pan terciado (trigo y cebada), semillas mayores (garbanzos, habas y alverjones) y excusado. Veamos algunas cuestiones de cada una de las mismas.

8 La serie de Hacimientos (arrendamientos) de rentas decimales tiene como fechas límites los años 1714 y 1837 , aunque hay destacadas lagunas, así faltan los años 1715-19, 1748-1753 y 1799-1831. Archivo Histórico Municipal de Jerez de la Frontera (A.H.M.J.F.), Sección Diezmos, Cajas 1-33.

9 Los diezmos del obispado de Cádiz recopilados por TRAVERSO RUIZ, Francisco. Los diezmos del obispado..., op.cit. volumen II, págs. 473-477.

10 Las dos formas de recaudar el diezmo eran mediante administración directa o por arrendamiento, dependiendo de cada diócesis la elección de una u otra fórmula. Era incluso habitual la convivencia de los dos procedimientos aplicado cada uno de ellos a una tipología de rentas decimales. El 23 de junio de 1798 el Consejo de Castilla prohibió los arrendamientos de los diezmos de granos, puesto que daban lugar a la concentración de un producto de primera necesidad en unos pocos individuos, lo que perjudicaba el comercio y favorecía el incremento de los precios. Dicha orden abogaba por la administración directa por parte del clero, puesto que "no era de creer que los eclesiásticos los dejasen (los granos) de vender en los tiempos en que más lo necesita el pueblo, reservándolos con el torpe deseo de aumentar su precio". Sobre esta cuestión BARRIO GOZALO, Maximiliano. op. cit., p. 134 y LARA RAMOS, Antonio. op. cit., p. 221. 
La renta de pan terciado no se arrendaba de forma conjunta mediante una única licitación, ya que la existencia en Jerez de la Frontera de ocho parroquias, así como de otras cuestiones peculiares, daba lugar a un mínimo de once subastas. Se arrendaba el pan terciado de: las parroquias de San Lucas; San Mateo; San Dionisio; San Marcos; San Juan; Santiago; primera, segunda y tercera parte de la de San Miguel $^{11}$; de forasteros ${ }^{12}$; y de Crespellina ${ }^{13}$. La octava parroquia, la colegial del Salvador, tenía privilegio para cobrar sus diezmos y entre sus partícipes no estaban ni el arzobispo ni el cabildo sevillano, por lo que procedía al arrendamiento de la renta de forma separada, no recogiéndose en los hacimientos estudiados. Además, durante el periodo analizado hay algunos años en los que también se arrienda el pan terciado del convento de la Cartuja; del convento del Espíritu Santo ${ }^{14}$; del colegio de los Jesuitas; de la nueva población de Algar $^{15}$; y de novales. El diezmo de pan terciado se arrendaba en especie, debiendo ser satisfecho por los arrendatarios entregando las dos terceras partes de las fanegas comprometidas en trigo y la tercera parte en cebada. Las subastas de pan terciado, siempre con carácter anual ${ }^{16}$, tenían lugar durante el mes de junio, debiendo estar cerradas las pujas y celebrados los remates el día primero de julio. Estas fechas propician un conocimiento real del estado de las cosechas, pues están a punto de recogerse, lo cual, por un lado, permite a la autoridad eclesiástica valorar la producción para fijar la postura inicial, y, por otro, limita el riesgo que corren los arrendatarios pues, salvo desastre imprevisto, pueden acomodar sus pujas a una estimación fiable. Por otro lado, el arzobispado de Sevilla limita de forma drástica el plazo temporal que tienen los arrendatarios para negociar con los granos recaudados, al imponer las fechas del 15 y 31 de agosto para abonar, respectivamente, las dos pagas comprometidas ${ }^{17}$. Será, por tanto, la

11 La división de la parroquia de San Miguel en tres partes se justifica por el hecho de que su feligresía representaba el 55\% de la total de la ciudad.

12 Los diezmos de forasteros hacen referencia a los diezmos de granos (pan terciado y semillas mayores) que debían contribuir los diezmadores con fincas situadas en Jerez en las parroquias de esta ciudad, aunque fueran vecinos de otras vicarías. Este privilegio lo tenían en el arzobispado de Sevilla sólo dos localidades: Jerez de la Frontera y Alcalá de Guadaira. MARTÍN RIEGO, Manuel. op. cit., p. 137.

13 Crespellina hace alusión a una antigua demarcación del término de Jerez, despoblada y sin existencia administrativa en el siglo XVIII, salvo para este aspecto del diezmo.

14 El pan terciado del convento del Espíritu Santo era mínimo, ya que era el recolectado en una pequeña hacienda que este convento, ubicado en El Puerto de Santa María, tenía en el término jerezano.

15 La nueva población de Santa María de Guadalupe de Algar se constituyó, con autorización del Consejo de Castilla, en 1773, por iniciativa de un comerciante que había adquirido más de 2.000 hectáreas de tierras públicas en Jerez unos años antes.

16 El carácter anual de los arrendamientos sigue la tónica general, aunque hay zonas en las que el arrendamiento suele ser por periodos superiores al año. En Galicia son corrientes los arrendamientos por tres años o más. EIRAS, Antonio. op. cit., p. 56.

17 MARTÍN RIEGO, Manuel. op. cit., p. 130. 
institución eclesiástica la que pueda beneficiarse de posibles subidas del precio del cereal durante el invierno o en los meses previos a la siguiente cosecha.

Al igual que ocurría con el pan terciado, la renta de semillas mayores se subastaba por parroquias, teniendo en cuenta que San Miguel, en este caso, no presenta división alguna y que la colegial del Salvador, por el privilegio ya comentado, no entra en estos hacimientos del arzobispado. Igualmente, se subasta la renta de semillas mayores de forasteros. El arrendamiento se hacía en dinero, por lo que el arrendatario debía recaudar las semillas (garbanzos, habas y alverjones) y, tras su venta, abonar el remate de la renta. El plazo de pago, dado que la institución eclesiástica ya no es la que negocia con el producto, se alarga, siendo la primera paga en navidad y la segunda y última en los días previos a la cuaresma (fecha variable entre febrero y marzo), hasta nueve meses después de la adjudicación.

La renta del excusado, es decir, los diezmos que en cada parroquia debía abonar la casa mayor diezmera, presenta cierta complejidad. En primer lugar, porque se suele hablar de un solo excusado, el debido al rey, cuando en bastantes diócesis era normal la existencia de un excusado eclesiástico. Así, en el arzobispado de Sevilla, al menos para el caso de Jerez de la Frontera lo hemos constatado, la documentación se refiere a un excusado mayor, que denomina escogido de Su Majestad, el cual se corresponde con la primera casa mayor diezmera, y a un excusado menor, segunda casa mayor diezmera, cuyo beneficiario es la fábrica de la santa iglesia catedral de Sevilla ${ }^{18}$.

En los hacimientos de rentas es el excusado menor de cada parroquia, incluyendo la colegial del Salvador, aquel que percibe la iglesia, el que se subasta, siempre en dinero. El arrendatario está obligado a satisfacer el importe en dos pagas, la primera el domingo de resurrección (marzo o abril) y la segunda el domingo de Pentecostés (mayo-junio), es decir, casi un año después del remate.

El excusado debido a la Hacienda Real, a pesar de que en la documentación siempre se especificaba cual era la casa escogida en cada parroquia, de lo cual se puede ver un ejemplo en el cuadro 1, no llegaba a recaudarse de forma individualizada como ocurría con el excusado de la fábrica de la catedral.

18 Esta duplicidad de excusados, el real y el destinado a la fábrica de la iglesia catedral de la demarcación, se observa, por ejemplo, en los obispados de Guadix y Cádiz. LARA RAMOS, Antonio. op. cit., p. 292 y TRAVERSO RUIZ, Francisco. Los diezmos del obispado..., volumen I, pág. 213. 


\section{Cuadro 1}

Escogidos y excusados en las parroquias de Jerez de la Frontera (1757 y 1788)

\begin{tabular}{|c|c|c|c|c|}
\hline Parroquia & Escogido 1757 & Escogido 1788 & Excusado 1757 & Excusado 1788 \\
\hline San Mateo & D. Luís Ponce & $\begin{array}{l}\text { D. Jerónimo } \\
\text { López }\end{array}$ & $\begin{array}{l}\text { D. Joaquín } \\
\text { Ponce }\end{array}$ & $\begin{array}{l}\text { D. Joaquín } \\
\text { Ponce }\end{array}$ \\
\hline San Lucas & $\begin{array}{c}\text { D. Agustín } \\
\text { Adorno Dávila }\end{array}$ & $\begin{array}{l}\text { D. Agustín Ador- } \\
\text { no }\end{array}$ & $\begin{array}{l}\text { Casa mortuo- } \\
\text { ria del mar- } \\
\text { qués de Campo } \\
\text { Real }\end{array}$ & $\begin{array}{l}\text { Marqués de } \\
\text { Campo Real }\end{array}$ \\
\hline San Juan & $\begin{array}{l}\text { D. Lorenzo de } \\
\text { Villavicencio }\end{array}$ & $\begin{array}{l}\text { D. Esteban Du- } \\
\text { begier }\end{array}$ & Pedro Romero & $\begin{array}{c}\text { D. Cristóbal de } \\
\text { Morales }\end{array}$ \\
\hline San Marcos & $\begin{array}{l}\text { D. Diego de } \\
\text { Morla }\end{array}$ & D. Juan Haurie & $\begin{array}{l}\text { D. Francisco } \\
\text { Romano }\end{array}$ & $\begin{array}{l}\text { D. Antonio Ro- } \\
\text { mano }\end{array}$ \\
\hline $\begin{array}{l}\text { San Dioni- } \\
\quad \text { sio }\end{array}$ & $\begin{array}{l}\text { D. Martín Ra- } \\
\text { mírez }\end{array}$ & $\begin{array}{c}\text { Rediezmos de } \\
\text { la ciudad }\end{array}$ & $\begin{array}{l}\text { D. Francisco } \\
\text { Ducoin de } \\
\text { Mendoza }\end{array}$ & $\begin{array}{l}\text { Rediezmos de } \\
\text { D. Bartolomé } \\
\text { Padilla }\end{array}$ \\
\hline San Miguel & $\begin{array}{l}\text { D. Esteban Ce- } \\
\text { sareo Martínez }\end{array}$ & D. Pablo Ribero & $\begin{array}{l}\text { Da Mariana } \\
\text { Ponce }\end{array}$ & D. Luís Ponce \\
\hline Santiago & $\begin{array}{l}\text { Juan García de } \\
\text { Castro }\end{array}$ & D. Lucas Cestelo & Álvaro Román & $\begin{array}{l}\text { D. Antonio Ro- } \\
\text { mán }\end{array}$ \\
\hline $\begin{array}{l}\text { Colegial del } \\
\text { Salvador }\end{array}$ & $\begin{array}{l}\text { Herederos de } \\
\text { D. Diego Dávila }\end{array}$ & $\begin{array}{l}\text { Marqués de } \\
\text { Casa Pabón }\end{array}$ & Juan García & Da Juana Dávila \\
\hline
\end{tabular}

Fuente: A.H.M.J.F., Sección Diezmos, Cajas 12 y 22

La mayor casa diezmera contribuía sus diezmos como cualquier otra casa, abonando lo que le tocaba por cada producto a los arrendatarios de las diversas rentas decimales. 
Esta práctica tiene como explicación la concordia establecida entre la Iglesia castellana y la Hacienda Real, mediante la cual, el rey renuncia al cobro directo del excusado percibiendo, a cambio, una cuota fija anual de la institución eclesiástica ${ }^{19}$. La situación descrita experimentó un cambio radical cuando, el 30 de diciembre de 1760, el monarca Carlos III emitió un real decreto para que desde 1761 el excusado se administrase de forma directa por la Real Hacienda, siguiendo las directrices marcadas por la instrucción promulgada el 24 de enero de 1761. La oposición de la Iglesia fue fuerte, ya que la medida significaba, para el conjunto de las diócesis castellanas, una pérdida de ingresos en torno a los 450.000 ducados $^{20}$. El 19 de marzo de 1775 una real orden, que atendía las muchas quejas eclesiásticas, permitía volver, a partir de 1776, al sistema de concordias, aunque elevando considerablemente el montante de la cuota a satisfacer por cada diócesis. Esta nueva etapa de administración del excusado regio se prolongará como mínimo hasta 1794, cuando un real decreto, emitido el 21 de marzo, ordenaba, a partir de 1795, la vuelta a la administración directa por la Real Hacienda, aunque respetando los años que, en cada demarcación, restaran de la última concordia acordada ${ }^{21}$.

En el arzobispado de Sevilla, y así se observa en la documentación jerezana, durante el periodo de concordias de 1776 a 1789 las autoridades eclesiásticas arrendaron de forma separada el excusado real, dividido en dos conceptos: el excusado de pan terciado, que se arrendaba en especie, y el de semillas mayores, ganado, miel, cera y vino, el cual se arren-

19 En el año 1567 el Papa Pío V concedía a Felipe II la gracia del excusado, que consistía en el producto decimal de la tercera casa diezmera de cada parroquia, con la finalidad de sufragar los gastos militares de las guerras contra turcos y herejes. El 21 de mayo de 1571 Pío V cambia la tercera por la primera casa diezmera. La gracia se fue prorrogando por periodos de 5 años. La contribución del excusado planteó problemas entre la Iglesia y la Hacienda Real, empeñada la segunda en cobrar las cantidades reales que correspondieran por la primera casa diezmera parroquial. La Iglesia, por su parte, planteaba llegar a un concierto o pago fijo. En agosto de 1572 se llegó al acuerdo de abonar, anualmente, 250.000 ducados en toda la corona de Castilla, aunque ello no terminó con las tensiones. El Papa Benedicto XIV concedió, el 6 de septiembre de 1757, la perpetuidad de la contribución del excusado. Sobre dicha renta ITURRIOZ MAGAÑA, Ángel. Estudio del subsidio y excusado (1561-1808). Contribuciones económicas de la Diócesis de Calahorra y La Calzada a la Real Hacienda, Logroño, Instituto de Estudios Riojanos, 1988.

20 Ya en el año 1756 se dio un primer intento de administración directa. La postura de la Iglesia contraria a la pérdida del control del excusado puede seguirse en el Memorial de la Iglesia de Toledo en su nombre y en el de todas las Iglesias y cabildos eclesiásticos de los reinos de Castilla y León, dirigido a S.M., pidiendo no lleve a la práctica la administración directa del Excusado. Año 1761, en Archivo Secreto Vaticano, Archivo de la Nunciatura de Madrid, vol. 131, folios 51-58, citado por BARRIO GOZALO, Maximiliano. op. cit., p. 167. La incapacidad del fisco real para recaudar el excusado le llevó a conceder su arrendamiento a la Compañía de los Cinco Gremios, aunque triplicando lo que venía percibiendo por la Iglesia.

21 En 1798 volvieron a permitirse concordias, aunque las realizadas quedaron anuladas al año siguiente. Sobre la incidencia de toda esta normativa en una diócesis concreta, la de Guadix, ver LARA RAMOS, Antonio. op. cit., PP. 289296. 
daba en dinero ${ }^{22}$. La información aportada por esta serie es fundamental para poder tener una idea aproximada de las cantidades detraídas de los diezmos por la Real Hacienda durante los años de administración directa del excusado, es decir los periodos de 1761 a 1775 y 1790 a 1798. Igualmente, teniendo en cuenta estos datos se pueden matizar algunos planteamientos que defienden, incluso, una reducción de la producción de cereales en la segunda mitad del siglo XVIII. Y es que, en el caso de Jerez de la Frontera, con ocho parroquias y por tanto con ocho primeras casas diezmeras, el excusado real representaba, en concepto de pan terciado, hasta un 16,44\% del conjunto de fanegas diezmadas. Y en torno al 6,6\% de la recaudación global de las rentas arrendadas en metálico ${ }^{23}$. La distribución de la propiedad en la Baja Andalucía, con predominio de la concentración en pocas manos, así como el sistema preferente de explotación de la tierra, mediante la cesión a grandes arrendatarios, da lugar a que las casas diezmeras excusadas representen una parte muy significativa de los diezmos ${ }^{24}$.

\section{DIEZMOS Y CÁLCULO DE LA PRODUCCIÓN AGRÍCOLA}

De un primer análisis de la documentación se obtiene quizás la conclusión más decepcionante: la imposibilidad de conocer la producción real de la localidad sirviéndonos de los diezmos. Y ello por varias razones. La primera, la gran cantidad de personas y predios que estaban exentos del pago de los diezmos. La fuente documental utilizada, los hacimientos de rentas, incluye siempre una relación de los mencionados exentos a fin de que los arrendatarios de las rentas supieran a quienes no debían exigir la contribución del diezmo, la cual en el periodo temporal estudiado se modifica según los años, como podemos comprobar en el cuadro 2, pero de forma poco sustancial.

22 En estos arriendos del excusado real, por el arzobispado de Sevilla, no se incluye la parroquia del Salvador, la cual, como ya hemos visto, tenía contabilidad independiente.

23 En esta misma línea, BARRIO GOZALO, Maximiliano. op. cit., p. 132, indica que «la administración de la casa excusada por cuenta de la Real Hacienda produjo una disminución de la masa decimal que se puede calcular de forma aproximada en el 8-10\% de los diezmos de granos y en un 30-35\% en los menudos». Por su parte, MUÑOZ DUEÑAS, María Dolores. op. cit., p. 365, calcula que «la detracción directa a partir de 1761 por Hacienda de la Casa Excusada, supone apartar del monto total de una diezmería una partida que puede llegar a ser importante (...). En 1765 el alcance del excusado de trigo representó el 14,2\% del total del año, y la cebada el 13,1\%». Y MELÓN JIMÉNEZ, Miguel Ángel. Extremadura en el Antiguo, p. 77, recalca como la detracción del excusado real incide, especialmente, en las cillas de los «centros urbanos en las que esa detracción dejaba fuera del total al mayor de los labradores o ganaderos».

24 No ocurría lo mismo en Galicia, donde la hegemonía de las pequeñas y medianas explotaciones, hace que la casa mayor diezmera se diferencie muy poco de las demás. Así se desprende del trabajo de FERNÁNDEZ GONZÁLEZ, Ángel I. Los mayores productores agrarios de Galicia en la segunda mitad del siglo XVIII, Revista de Historia Económica, año XII, 2 (1994), PP. 365-395. 


\section{Cuadro 2}

Instituciones, personas y productos exentos de satisfacer el diezmo (años 1757 y 1788)

\begin{tabular}{|c|c|c|}
\hline Exentos & 1757 & 1788 \\
\hline $\begin{array}{l}\text { Diezmos y rediezmos de los señores prebendados, y los rediezmos de } \\
\text { todas las tierras, cortijos y heredades ajenas que tuvieren en arren- } \\
\text { damiento y labraren a sus expensas }\end{array}$ & $\mathrm{X}$ & $\mathrm{X}$ \\
\hline Diezmos de los Colegios de la Compañía de Jesús & $\mathrm{X}$ & \\
\hline $\begin{array}{l}\text { Diezmos personales y prediales que se causen en tierras y ganados } \\
\text { que fueron de los padres de la Compañía de Jesús y se mantienen y } \\
\text { cultivan a expensas de temporalidades }\end{array}$ & & $\mathrm{X}$ \\
\hline Diezmos del monasterio de la Cartuja & $\mathrm{X}$ & \\
\hline Rediezmos del monasterio de la Cartuja & & $\mathrm{X}$ \\
\hline Diezmos del convento Madre de Dios & $\mathrm{X}$ & \\
\hline Diezmos de los colonos del convento de religiosas Madre de Dios & & $\mathrm{X}$ \\
\hline $\begin{array}{l}\text { Diezmos de los conventos de Santo Domingo; de la Merced; de San } \\
\text { Juan de Dios; de San Jerónimo de Bornos; de San Agustín de El Puerto } \\
\text { de Santa María }\end{array}$ & $\mathrm{X}$ & \\
\hline $\begin{array}{l}\text { Diezmos de conventos de religiosos y religiosas que se causen en esta } \\
\text { vicaría, así en tierras propias como en ajenas que tengan en arren- } \\
\text { damiento }\end{array}$ & & $\mathrm{X}$ \\
\hline Diezmos de cualquier religioso particular & $\mathrm{X}$ & $\mathrm{X}$ \\
\hline $\begin{array}{l}\text { Diezmos de las dehesas de Verlanga, Verlanguilla, Suara y Dehesa Bo- } \\
\text { yar, que se incluyen los de ganados que en ellas nacieren y pastaren }\end{array}$ & $\mathrm{X}$ & $\mathrm{X}$ \\
\hline $\begin{array}{l}\text { Diezmos que se causaren en Torno del Álamo y Vega Romana, tér- } \\
\text { mino de Jerez y los que se causaren en la Vega de El Puerto de Santa } \\
\text { María }\end{array}$ & $\mathrm{X}$ & \\
\hline \multicolumn{3}{|l|}{ Continúa en la siguiente página... } \\
\hline
\end{tabular}




\begin{tabular}{|c|c|c|}
\hline $\begin{array}{l}\text { Diezmos que se causaren en las tierras que en la parte de Jerez, diez- } \\
\text { matoría de este arzobispado, ha dejado el río Guadalete en la rotura } \\
\text { que éste hizo por enero de } 1747\end{array}$ & $\mathrm{X}$ & \\
\hline Diezmos del cortijo de la Dehesilla, propio de D. Agustín Adorno & $\mathrm{X}$ & $\mathrm{X}$ \\
\hline $\begin{array}{l}\text { Diezmos causados en heredades, cortijos, huertas y tierras propias } \\
\text { de la Santa Iglesia }\end{array}$ & $\mathrm{X}$ & $\mathrm{X}$ \\
\hline Diezmos de las tierras y heredades de D. Martín Dávila Sigüenza & $\mathrm{X}$ & \\
\hline Diezmos de las tierras novales del término de Jerez & $\mathrm{X}$ & \\
\hline $\begin{array}{l}\text { Diezmos de ganados de diferentes vecinos de Ubrique, Grazalema, } \\
\text { Benaocaz y Villaluenga término espiritual de la Santa Iglesia de la } \\
\text { ciudad de Málaga; y de otros obispados que labran en término de } \\
\text { Jerez }\end{array}$ & $\mathrm{X}$ & $\mathrm{X}$ \\
\hline Diezmos que causare D. Juan Vicente Gil de Molina, vecino de Jerez & $\mathrm{X}$ & \\
\hline Diezmos de ganados que causare el Marqués de las Amarillas & $\mathrm{X}$ & \\
\hline $\begin{array}{l}\text { Diezmos de aves; diezmos de grana; y diezmos de higos de tuna que } \\
\text { se causaren en esta vicaría }\end{array}$ & & $\mathrm{X}$ \\
\hline $\begin{array}{l}\text { Diezmos de alcaceres que cause la ciudad de Jerez, así a su nombre } \\
\text { como al de otro cualquier particular a quien dicha ciudad tenga } \\
\text { arrendado dichos alcaceres }\end{array}$ & & $\mathrm{X}$ \\
\hline Diezmos de uva de la viña de la casa mortuoria de D. Tello de Torres & & $\mathrm{X}$ \\
\hline Diezmos personales de Manuel Polo, vecino de El Puerto & & $\mathrm{X}$ \\
\hline Diezmos de las viñas de D. Antonio Díaz & & $\mathrm{X}$ \\
\hline $\begin{array}{l}\text { Diezmos personales que causen los vecinos de la nueva población de } \\
\text { Santa María de Guadalupe de Algar y los prediales que se causen en } \\
\text { las tierras de la nueva población así por sus vecinos como por otros } \\
\text { forasteros }\end{array}$ & & $\mathrm{X}$ \\
\hline
\end{tabular}

Fuente: A.H.M.J.F., Sección Diezmos, Cajas 12 y 22 
¿Cuánto podían significar estas exenciones sobre el volumen global de la producción? La respuesta a esta cuestión no es fácil, pues depende de la estructura económica y de la distribución de cultivos en cada localidad, pero algunas investigaciones apuntan a que, sólo en el capítulo de granos, se podría estimar, como mínimo entre un 10-15\% de la cosecha ${ }^{25}$. En el caso de Jerez de la Frontera, los eclesiásticos poseían, a nivel patrimonial o beneficial, hasta un 21\% de las tierras dedicadas al cereal ${ }^{26}$, todas las cuales, según se desprende de la relación anterior, estaban exentas del pago del diezmo, por lo que resulta factible que un porcentaje similar de la cosecha final de trigo y cebada no se compute en las cuentas decimales. Es más, sería posible apuntar, incluso, un tanto por cierto superior, ya que, además de la mejor calidad de las tierras de los eclesiásticos, hay que tener en cuenta que las fincas que éstos tuvieran tomadas en arrendamiento tampoco contribuían al diezmo. Aquí se podría llegar hasta el fraude, al aparecer como arrendatario nominal de una explotación un eclesiástico con la única finalidad de liberar la producción de la carga decimal. Se plantea, pues, un tema muy interesante para profundizar en el mismo.

Y los eclesiásticos, como vimos en el cuadro 2, sólo son una parte de los exentos en la localidad de Jerez de la Frontera, donde también dejan de satisfacer el diezmo determinados propietarios seglares o algunas tierras concretas. Así, por ejemplo, unas 425 fanegas de trigo-cebada, que se corresponderían con 4.250 fanegas de producción, entre un 1-2\% de la cosecha global de cereales, escapan a la contribución decimal por los privilegios que ostentan diversos propietarios particulares ${ }^{27}$. Por último, los diezmos novales, aquellos producidos en las tierras de nueva roturación, tampoco se incluyen en la contabilidad eclesiástica y, en ocasiones, pueden representar montantes significativos. En el trienio 1735-1737, la documentación manejada hace referencia a dichos diezmos novales, que alcanzan una media anual de 531 fanegas, por lo que volvemos a calcular entre un 1-2\% de la cosecha global. En resumen,

25 BARRIO GOZALO, Maximiliano. op. cit., pp. 98-100, señala para la tierra de Segovia un porcentaje del 10,38\% de la cosecha, aunque en algunas vicarías concretas se sobrepasaba el 25\%. En 15 localidades de la diócesis de Palencia, la media de la producción exenta era del 14,4\%, superándose el 20\% en cuatro de ellas, MARCOS MARTÍN, Alberto. De nuevo sobre los diezmos. La documentación decimal de la diócesis de Palencia: problemas que plantea, Investigaciones Históricas: Época Moderna y Contemporánea, 4 (1983), Pp. 99-122. El 8 de junio de 1796 una real cédula ordenaba aplicar el Breve de Pío VI, emitido el 8 de enero, por el que se anulaban todas las exenciones de pagar diezmos concedidas por privilegio o impuestas por la costumbre inmemorial, exceptuándose aquellas que tenían título oneroso. Quizás por esta medida, en el obispado de Córdoba, en 1810, la partida de exentos sólo alcanzaba el 8\% del diezmo del trigo y el 5\% del de la cebada. MUÑOZ DUEÑAS, María Dolores. op. cit., p. 365.

26 Datos obtenidos del análisis de la documentación del Catastro de Ensenada, 1755. A.H.N., Fondo histórico del Ministerio de Hacienda, libros 7.494 y 7.496.

27 Dato tomado de las Respuestas Generales del Catastro de Ensenada, Jerez de la Frontera, 1752. Editadas por ORELLANA, Cristóbal. El Catastro de Ensenada en Jerez de la Frontera (1755), Revista de Historia de Jerez, 8 (2002), pp. 3-51. 
los diezmos de granos exentos de eclesiásticos, particulares y novales, pueden importar en torno al 25\% del cómputo global de la cosecha de trigo y cebada de Jerez de la Frontera.

El segundo aspecto que limita el conocimiento real de la producción a través de la contabilidad de los diezmos es la incidencia del fraude y de la resistencia a los pagos. Y es que, a pesar de las graves penas de carácter espiritual impuestas a los infractores ${ }^{28}$, el fraude y el impago fueron prácticas habituales, que se fueron acentuando durante la última etapa de vigencia de los diezmos, sin que se pueda descartar su influencia en el estancamiento e, incluso, descenso de las recaudaciones decimales a partir de la segunda mitad del siglo XVIII $^{29}$. Un decreto emitido, en 1743, por el obispo de Segovia, D. Diego García Moreno, hace referencia a las prácticas fraudulentas, al indicar que:

"sin embargo de los repetidos mandatos se encuentran muchos que todos los granos de su cosecha los levantan en montones $\gamma$ meten en las casas antes de diezmar; otros, que aunque miden cada montón es colmando las medidas $\gamma$ sin rasar, $y$ para pagar el diezmo lo hacen con medida rasada; otros, cogiendo de buena, mala $\gamma$ mediana calidad, reservan lo mejor para sí $\gamma$ pagan de lo demás el diezmo de todo; $\gamma$ lo peor es que algunos curas que debían velar por cosas tan delicadas $\gamma$ concernientes a la salvación de sus feligreses cooperan a estos fraudes, componiéndose con los labradores".

Escritos que son comunes en otras diócesis ${ }^{30}$. En la documentación sobre diezmos conservada en el archivo de Jerez de la Frontera, no resulta difícil encontrar quejas de los arrendatarios de las rentas decimales que muestran su contrariedad ante la resistencia de algunos vecinos al pago de los diezmos. Así, el presbítero D. Juan José Genís, arrendatario de varias rentas de pan y semilla, manifestaba en un escrito fechado en julio de 1742, como...

28 El pagar tarde era considerado pecado mortal y el defraudar o no pagar tenía pena de excomunión y privación de sepultura eclesiástica. MARTín RIEGO, Manuel. op. cit., p. 73.

29 Así lo señala ARDIT LUCAS, Manuel. Recaudación y fraude decimal en el siglo XVIII valenciano, en Estructuras agrarias y reformismo ilustrado en la España del siglo XVIII, Madrid, MAPA, 1989, PP. 391-410. Sobre el fraude en el obispado de Cádiz puede consultarse el artículo de TRAVERSO RUíZ, Francisco. Una disidencia significativa: el impago del diezmo en el obispado de Cádiz (siglos XVII-XIX), Hispania Sacra, XXXIX (1987), PP. 201-210.

30 Recogido por BARRIO GOZALO, Maximiliano. op. cit., p. 102. Para el arzobispado de Sevilla, MARTÍN RIEGO, Manuel. op. cit, p. 100. Y para la diócesis de Coria, MELón JIMÉNEZ, Miguel Ángel. “Los diezmos de la diócesis de Coria (15661773)", Studia Histórica. Historia Moderna, 5 (1987), pp. 177-191, que recoge para el periodo 1701-1765 hasta 65 pleitos motivados por la recaudación del diezmo. 
"diferentes diezmadores a dichas rentas se excusan a pagar el diezmo y otros no pagan lo que legítimamente deben, excusándose por varios $\gamma$ frivolos pretextos" ${ }^{\prime \prime 3}$.

Ahora bien, se conoce su existencia, pero resulta muy difícil evaluar el montante de este fraude, ni siquiera de forma aproximada, por lo que dar cualquier porcentaje sobre el conjunto de la cosecha es, cuanto menos, imprudente.

Por último, la documentación decimal analizada impide conocer la producción real al contabilizar el resultado de una subasta al mejor postor, y no la recaudación directa y efectiva del 10\% de la cosecha recolectada. Incluso, en bastantes rentas, el arrendamiento y, por tanto, el pago, se hace en metálico, por lo que, al introducirse otros factores, tales como el precio de mercado, enmascaran el producto final recolectado. Es lo que ocurre, por ejemplo, con el excusado (incluida su parte de pan terciado), las semillas mayores y menores o el vino. En definitiva, las cantidades percibidas por la administración eclesiástica mediante el arrendamiento de las rentas decimales marcan, en todo caso, un nivel básico de producción, puesto que lo realmente recaudado por el arrendatario debe permitirle a éste, no sólo satisfacer el montante del remate, sino sufragar los gastos de la cobranza y obtener unos beneficios acordes con los riesgos y cuantía de la operación. Sobre esta cuestión, el trabajo del profesor Eiras sobre los diezmos en Galicia plantea situaciones muy dispares, que se mueven entre malos negocios que dan lugar a pérdidas y arrendamientos que producen beneficios superiores al 50\%. Concluye que el valor modal se situaba en torno a unos beneficios del 20-30\%, se entiende sin descontar los gastos, que rondarían el 4-6\% ${ }^{32}$. En definitiva una ganancia neta entre el 15-25\%, muy superior al interés oficial del crédito que estaba en el $3 \%$ y, también, por encima de las tasas medias de beneficio de la propia actividad agrícola. Es esta alta rentabilidad la que origina, en muchas ocasiones, una fuerte puja para hacerse con los arrendamientos. En el caso de Jerez de la Frontera, para la renta de pan terciado, la media de incremento del remate final con respecto a la cantidad de salida se sitúa, en el periodo temporal estudiado, en un 21,08\%. Pero se puede concretar mucho más. De un total de 69 años, hubo 13, el 18,84\%, en los cuales los postores no arriesgaron, desistieron de pujar y la renta tuvo que ser llevada en fieldad por la propia administración eclesiástica. En otros 9

31 A.H.M.J.F., Sección diezmos, Caja 50, exp. 263.

32 EIRAS, Antonio. op. cit., pp. 70-72. De todas formas, cada territorio tiene sus peculiaridades, ya que los arrendamientos en Galicia se solían hacer por tres años (en Sevilla por un año), lo que aumenta los riegos al desconocer las cosechas futuras, pero permiten negociar con los granos recaudados durante un año (en Sevilla sólo un mes). Los gastos de administración los hemos asimilado a los porcentajes que se registran en el cobro de las rentas estatales y municipales. Sólo las tasas anexas al proceso de arrendamiento podían alcanzar el 1\%. Ver MARTÍN RIEGO, Manuel. op. cit., p. 150. 
años, el 13,04\%, ninguna puja sobrepasó el montante de salida o lo hizo en cuantía menor al 5\%. Otros 24 años, el 34,78\%, las pujas incrementaron entre un 6 y un 21\% la cantidad de partida, son anualidades en las que no se llegó a la media del periodo. Finalmente, en un total de 23 años, el 33,34\%, las pujas fueron muy disputadas, sobrepasándose el incremento medio del 21\%, y contabilizándose 7 de dichos años con remates entre un 40 y 50\% por encima de la postura inicial. Y un año excepcional, el de 1742, en cual se llegó al 84,76\%, lo que supuso arrendar la renta de pan terciado en 26.487 fanegas, cuando la cantidad de salida se situaba en tan sólo 14.336 fanegas, por lo que hay más de 12.000 fanegas de incremento.

Volviendo a la cuestión de la producción real, hay que recordar, igualmente, que la documentación utilizada corresponde al arzobispado de Sevilla, por lo que no incluye los diezmos generados en las tierras del término pertenecientes al obispado de Cádiz, ni tampoco las rentas decimales de la parroquia colegiata del Salvador que, como ya se comentó, se administran de forma separada. Lo mismo que la renta de pan terciado de forasteros.

En resumen, en el caso concreto de la renta decimal de pan terciado (trigo y cebada), para poder conocer el monto total de la cosecha en la localidad de Jerez de la Frontera habría que sumar a la cantidad recaudada mediante la subasta los siguientes porcentajes: entre un 15-25\% del teórico beneficio del arrendatario de la renta; en torno a un 25\% que dejan de contribuir los exentos; un 10\% que sería el de la producción de la parte del término que corresponde al obispado de Cádiz; un 15\% por lo percibido por la colegial del Salvador; otro 10\% que se correspondería a la parte de pan terciado abonada en dinero en la renta del excusado menor o de la fábrica ${ }^{33}$; otro $15 \%$ de lo abonado, en arrendamiento y cuenta separada, por los labradores forasteros, es decir, no vecinos de la localidad; y a todo ello el porcentaje indeterminado que representa el posible fraude y los impagos. Es decir, sin contar con este último imponderable, la cosecha real de granos del término jerezano sería, aproximadamente, del doble de la que se desprende de los datos contables manejados.

Así, si la recaudación media anual del diezmo de pan terciado en el periodo 1720-1798 fue de 18.500 fanegas, lo que correspondería a una recolección de 185.000 fanegas de trigo y cebada, la cosecha real debería situarse en torno a las 370.000 fanegas. Mediante la información aportada por las Respuestas Generales del Catastro de Ensenada, en cuanto a extensión de terreno

33 En el periodo 1761-1775 hay que incluir, además, otro 15\% correspondiente al excusado mayor o "escogido de S.M.", por haberse administrado directamente por la Hacienda Real dichos años. 
dedicado a cada aprovechamiento agrario, los sistemas de cultivo practicados y los rendimientos de las simientes según las calidades de la tierra, se puede hacer un cálculo sobre la teórica producción en la localidad de Jerez de la Frontera a mediados del siglo XVIII. El resultado es el siguiente: 302.954 fanegas de trigo y 122.768 fanegas de cebada, lo que implica un total de 425.722 fanegas $^{34}$. Por otro lado, se cuenta con estadísticas de las cosechas para los años 178790, periodo durante el cual la media de la producción anual de trigo fue de 361.953 fanegas, siendo la de cebada de 62.243 fanegas, por lo que la suma alcanza un total de 424.196 fanegas, teniendo en cuenta que hubo una cosecha corta, dos normales y una muy buena ${ }^{35}$. Se aprecia, tanto en los datos del Catastro de Ensenada como en los estadísticos, un ligero aumento, en torno al 15\%, sobre la estimación teórica de la cosecha según los datos decimales rectificados, diferencia que puede ser debida a una apreciación a la baja en algunos de los factores de rectificación (exentos, contabilidades separadas, ...) y-o, quizás, a la incidencia de la defraudación.

\section{EPÍLOGO}

Otros aspectos se podían haber planteado tras el análisis de la documentación, en especial todo lo referido al mundo de las subastas, las pujas, los arrendatarios de rentas, pero ello resultaría demasiado amplio para la extensión limitada establecida por el comité editorial para los artículos de este volumen.

Puede que lo que se aporte en este trabajo fuera ya conocido, pero no conviene olvidar la necesidad de estudios de ámbito geográfico reducido que nos descubran detalles concretos y sobre todo pongan en entredicho las conclusiones obtenidas gracias a una documentación más general que no recoge matices como los exentos de cada localidad, con la significación de los mismos en el montante global de los diezmos, y, de forma especial, el peso de los excusados en localidades como Jerez de la Frontera, con varias parroquias y una actividad agrícola basada en las grandes explotaciones propias o arrendadas.

Terminar deseándole a los compañeros del Departamento Manuel Bustos Rodríguez, Fernando Pérez Mulet y Juan Ramón Cirici Narváez una descansada y merecida jubilación. Ha sido todo un privilegio compartir muchos años de docencia con ellos.

34 Las respuestas generales en ORELLANA, Cristóbal. op. cit., pp. 3-51. Los cálculos sobre la producción en GONZÁLEZ BELTRÁN, Jesús Manuel. El fruto de la tierra. La producción agrícola en Jerez de la Frontera a fines de la Edad Moderna, Revista de Historia de Jerez, 14/15 (2008/09), pp. 107-122.

35 Los datos estadísticos en A.H.M.J.F., leg. 265, exp. 8.144. 